\title{
Network analysis of microRNA and mRNA seasonal dynamics in a highly plastic sensorimotor neural circuit
}

\author{
Tracy A. Larson 1,2, Karin L. Lent ${ }^{3}$, Theo K. Bammler ${ }^{4}$, James W. MacDonald ${ }^{4}$, William E. Wood ${ }^{5,6,7}$, \\ Melissa L. Caras ${ }^{3,6,8}$, Nivretta M. Thatra ${ }^{1,3}$, Agata Budzillo ${ }^{5,6}$, David J. Perkel ${ }^{1,5}$ and Eliot A. Brenowitz ${ }^{1^{*}}$
}

\begin{abstract}
Background: Adult neurogenesis and the incorporation of adult-born neurons into functional circuits requires precise spatiotemporal coordination across molecular networks regulating a wide array of processes, including cell proliferation, apoptosis, neurotrophin signaling, and electrical activity. MicroRNAs (miRs) - short, non-coding RNA sequences that alter gene expression by post-transcriptional inhibition or degradation of mRNA sequences - may be involved in the global coordination of such diverse biological processes. To test the hypothesis that miRs related to adult neurogenesis and related cellular processes are functionally regulated in the nuclei of the avian song control circuit, we used microarray analyses to quantify changes in expression of miRs and predicted target mRNAs in the telencephalic nuclei HVC, the robust nucleus of arcopallium (RA), and the basal ganglia homologue Area X in breeding and nonbreeding Gambel's white-crowned sparrows (Zonotrichia leucophrys gambelli).
\end{abstract}

Results: We identified 46 different miRs that were differentially expressed across seasons in the song nuclei. miR-132 and miR-210 showed the highest differential expression in HVC and Area X, respectively. Analyzing predicted mRNA targets of miR-132 identified 33 candidate target genes that regulate processes including cell cycle control, calcium signaling, and neuregulin signaling in HVC. Likewise, miR-210 was predicted to target 14 mRNAs differentially expressed across seasons that regulate serotonin, GABA, and dopamine receptor signaling and inflammation.

Conclusions: Our results identify potential miR-mRNA regulatory networks related to adult neurogenesis and provide opportunities to discover novel genetic control of the diverse biological processes and factors related to the functional incorporation of new neurons to the adult brain.

Keywords: microRNA, miR-mRNA network, Adult neurogenesis, Seasonal plasticity, Sex steroids, Testosterone, Photoperiod, Songbird, Bird song

\section{Background}

Ongoing neurogenesis in the adult brain requires complex but yet precise temporal and spatial coordination of the underlying processes and mechanisms. For example, neural stem cells residing in specific niches throughout the adult brain [1-4] proliferate and give rise to new neurons and glia [5]. The new immature neurons depart the neurogenic niche, migrate to their final destinations $[5,6]$, and integrate into functional circuits $[5,7-9]$.

\footnotetext{
*Correspondence: eliotb@u.washington.edu

'Department of Biology, University of Washington, Seattle, WA 98195, USA Full list of author information is available at the end of the article
}

Once fully integrated mature adult-born neurons persist for periods ranging from days to years [5, 10-12]. Each of these processes is regulated by a plethora of interacting autonomous and non-autonomous factors. Some of these factors include but are not limited to sex steroid hormones secreted by the gonads and synthesized de novo in the brain, locally synthesized neurotrophins, neural use and activity, cell death and inflammation, behavior including social interactions, and stress (for reviews see $[5,13])$.

One potential candidate for globally regulating the different biological processes, mechanisms, and factors associated with adult neurogenesis is microRNAs (miRs). 
miRs are short, non-coding RNA sequences that alter gene expression by translational repression or mRNA target degradation (for review see [14]). Individual miRs have many mRNA targets, and thus can act as global regulators of complex temporal and spatial patterns of gene or protein expression changes underlying neural plasticity [14]. Moreover, miR expression is highly enriched in the brain [15] and has been implicated as involved in a variety of neurological disorders and diseases including Amyotrophic Lateral Sclerosis [16], Fragile X mental retardation [17], mood and mental disorders [18, 19], and Alzheimer's Disease [20]. Specific miRs play major roles in the normal processes of neural plasticity including fate specification [21], dendritic arborization and synapse formation [22, 23], adult-born neuronal addition and survival [24], and apoptosis [25]. However, potential genetic regulatory networks of brainexpressed miRs have been little explored in the context of adult neural circuit plasticity.

One prominent model for adult neurogenesis is the song control circuit of songbirds (Fig. 1a). Adult neurogenesis in Area X, a basal ganglia homologue required for song learning [26], occurs at high constitutive rates [27]. On the other hand, adult neurogenesis in HVC, a pallial nucleus involved in song learning and production, exhibits pronounced seasonal changes in neuronal addition and neuronal loss (reviewed in [13]). Most, if not all, of the new neurons added to the adult HVC have

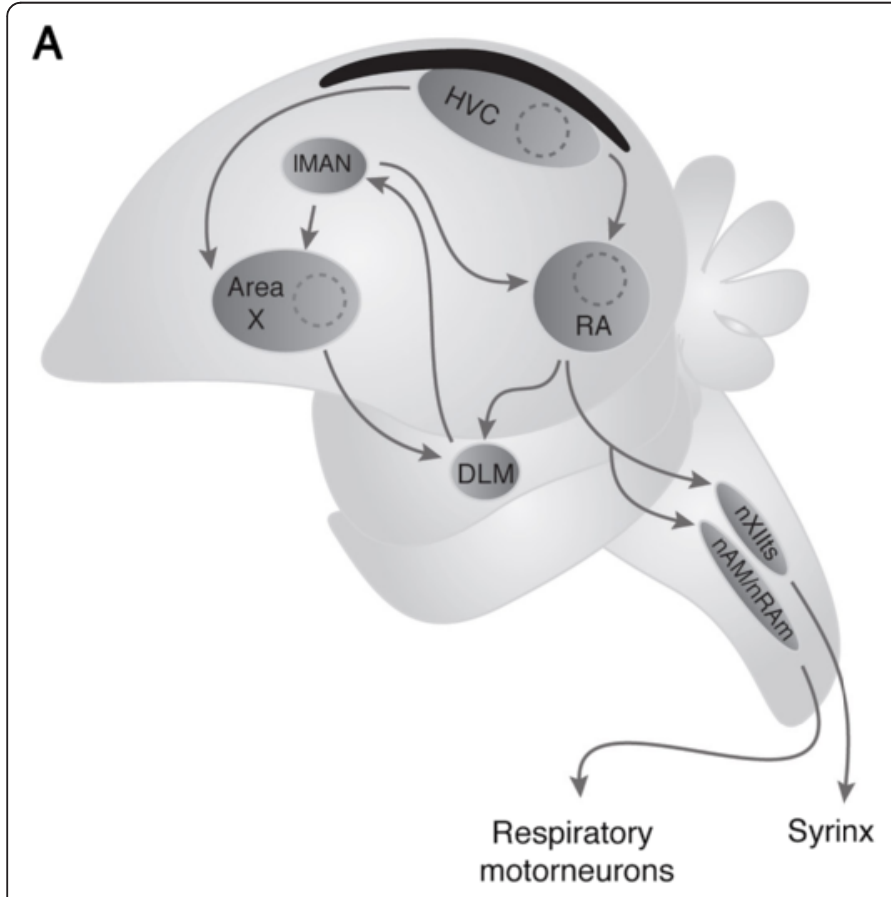

C

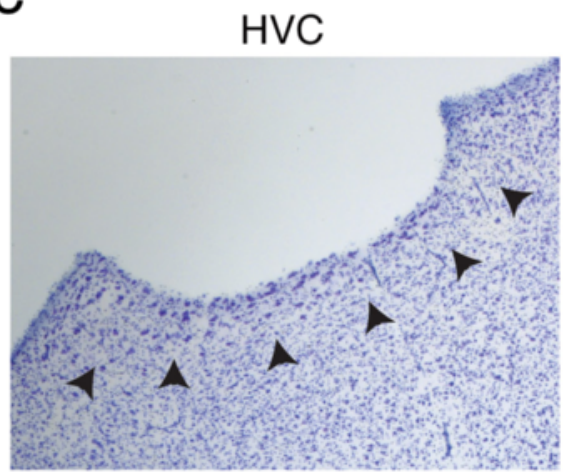

B
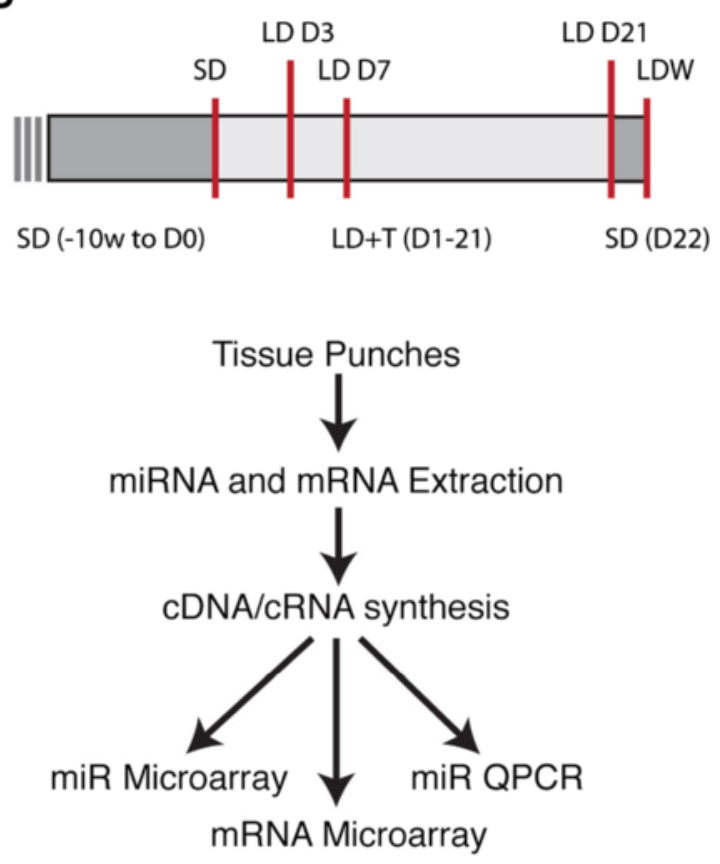

Fig. 1 Experimental design. a A schematic of the song nuclei sampled for microarray analysis. The dotted line indicates where tissue samples were obtained. $\mathbf{b}$ Experimental time-line for all experimental groups. A red line indicates termination of the experiment for the given group. c Representative images of Nissl-stained brain sections confirming tissue punch locations in HVC, RA and Area X. The arrowheads indicate the borders of the respective nuclei as determined by cell morphology and density 
long axons that project $4 \mathrm{~mm}$ or more to synapse on target cells in RA [28, 29]. During the breeding season total neuronal number in HVC of Gambel's white-crowned sparrow (Zonotrichia leucophrys gambelii) increases by $25 \%$ (nearly 68,000 neurons), due to increased addition of adult-born neurons [30-32]. As white-crowned sparrows transition back into nonbreeding conditions, HVC neuronal number decreases through caspase-mediated apoptosis of neurons [33-35]. The seasonal incorporation of new HVC neurons of adult birds, correlates with changes in song production - a learned sensorimotor behavior; each breeding season as HVC increases in neuronal number, song production rate and song stereotypy increase $[28,36,37]$. Concomitant with the changes in HVC morphology and singing behavior, both Area X and RA change in morphology $[27,32,33]$ and RA in neuronal activity during breeding seasons $[38,39]$. The quantitative changes in HVC neuronal number, the incorporation of adult-born neurons into long-range neural circuits, and the tight relationship between HVC adult neurogenesis, morphological and physiological changes in other song nuclei, and the production of a learned sensorimotor behavior, make the HVC $\rightarrow$ RA and HVC $\rightarrow$ Area X circuits a unique model for investigating the spatiotemporal pattern of genetic networks that regulate the multitude of processes and factors related to adult neural circuit plasticity.

\section{Methods}

Animals

All animal procedures were approved by the Institutional Animal Care and Use Committee at the University of Washington. Sixty adult male Gambel's white-crowned sparrows (Zonotrichia leucophrys gambelii) were collected in eastern Washington during their spring and autumnal migration under State of WA Scientific Collecting permit \#10-162 and U.S. Fish and Wildlife Permit \#MB708576-0. Birds were housed in outdoor aviaries under natural photoperiods for at least 20 weeks prior to transitioning into indoor aviaries. Once indoors, birds were exposed to a short-day photoperiod (SD; $8 \mathrm{~h}$ light: $16 \mathrm{~h}$ dark) for at least 10 weeks prior to experiment onset to ensure that they were photosensitive and responsive to sex steroid hormones. Food and water were available ad libitum throughout the experiment. We castrated all birds by anesthetizing them with isoflurane, making a small incision on the left side anterior to the caudal-most rib and dorsal to the uncinate process, and aspirating both testes [40].

To synchronize the physiological states of the birds, birds were implanted with a subcutaneous Silastic pellet (i.d. $1.0 \mathrm{~mm}$; o.d. $2.0 \mathrm{~mm}$; length: $12 \mathrm{~mm}$; VWR) filled with crystaline $\mathrm{T}$ (Sigma) and shifted to a long day photoperiod (LD; $20 \mathrm{~h}$ light: $4 \mathrm{~h}$ dark) for 21 days (see Fig. $1 \mathrm{~b}$ for experimental design). A period of 21 days in breeding-like conditions is adequate for full breedinglike growth of the song circuits [32]. On day 21 we removed the subcutaneous $\mathrm{T}$ pellets from all birds, and shifted them back to SD photoperiods for 10 weeks. On the final day of SD we quickly decapitated nine birds and removed the brain for processing as detailed below. The SD group of birds represented the steady-state regressed song control circuit and served as a baseline of comparison for all other groups. Another group of 45 birds were transitioned back to LD photoperiods and implanted with $\mathrm{T}(\mathrm{LD}+\mathrm{T})$. On days 3,7 , and 21 of $\mathrm{LD}$ $+\mathrm{T}$ exposure, we quickly decapitated nine birds from each group and removed the brain. Of the nine remaining birds in $\mathrm{LD}+\mathrm{T}$ for 21 days, all had $\mathrm{T}$ pellets removed and were transitioned back to $\mathrm{SD}$ overnight (i.e. LDW condition). After 1 day in SD, all nine remaining birds were killed for tissue collection. All birds were allowed to sing throughout the course of the entire experiment. SD and LDW birds sing less stereotyped song and do so less frequently than $\mathrm{LD}+\mathrm{T}$ birds [37]. There is extensive variability in song rate within and between individual birds over a given day, and from day to day, under $\mathrm{LD}+\mathrm{T}$ conditions [41]. To control for circadian effects on genes and behavior, we killed all birds between 4 and $8 \mathrm{~h}$ after lights on.

\section{Tissue harvesting}

The brains of all birds were removed rapidly (within $1 \mathrm{~min}$ ) and Vibratome sectioned at $300 \mu \mathrm{m}$ in ice-cold, oxygenated artificial cerebral spinal fluid (ACSF; $119 \mathrm{mM} \mathrm{NaCl}, 2.5 \mathrm{mM} \mathrm{KCl}, 1.3 \mathrm{mM} \mathrm{MgSO} 4,2.5 \mathrm{mM}$ $\mathrm{CaCl} 2,1 \mathrm{mM}$ NaH2PO4, $16.2 \mathrm{mM}$ NaHCO3, $11 \mathrm{mM}$ Dglucose, and $10 \mathrm{mM}$ HEPES). From these slices, punches of tissue containing HVC, RA, or Area X were collected within 2 min under a dissecting microscope using blunted hypodermic needles of the minimum gage that could fit entirely within the target nucleus. Tissue punch location was verified post-hoc by Nissl-staining of resectioned, fixed tissue, as in (Fig. 1c; [42]). HVC punches included the proliferative ventricular zone just dorsal to HVC. All of tissue punches from one nucleus of one bird were pooled, flash frozen in dry ice, and stored at $-80{ }^{\circ} \mathrm{C}$ until processed for microarray hybridization.

\section{RNA isolation to microarray hybridization}

Total RNA was extracted from individual snap frozen tissue samples using the mirVana Paris Kit according to the manufacturer's protocol (Life Technologies, PN $1556 \mathrm{M} \mathrm{Rev} \mathrm{C)} \mathrm{to} \mathrm{generate} \mathrm{samples} \mathrm{of} \mathrm{isolated} \mathrm{small}$ ( $<200$ nucleotides) and large ( $>200$ nucleotides) RNAs. Total RNA concentration was determined measuring OD260, and the integrity of each RNA sample was verified using an Agilent 2100 Bioanalyzer (Santa Clara, CA). Only RNA samples with appropriate size 


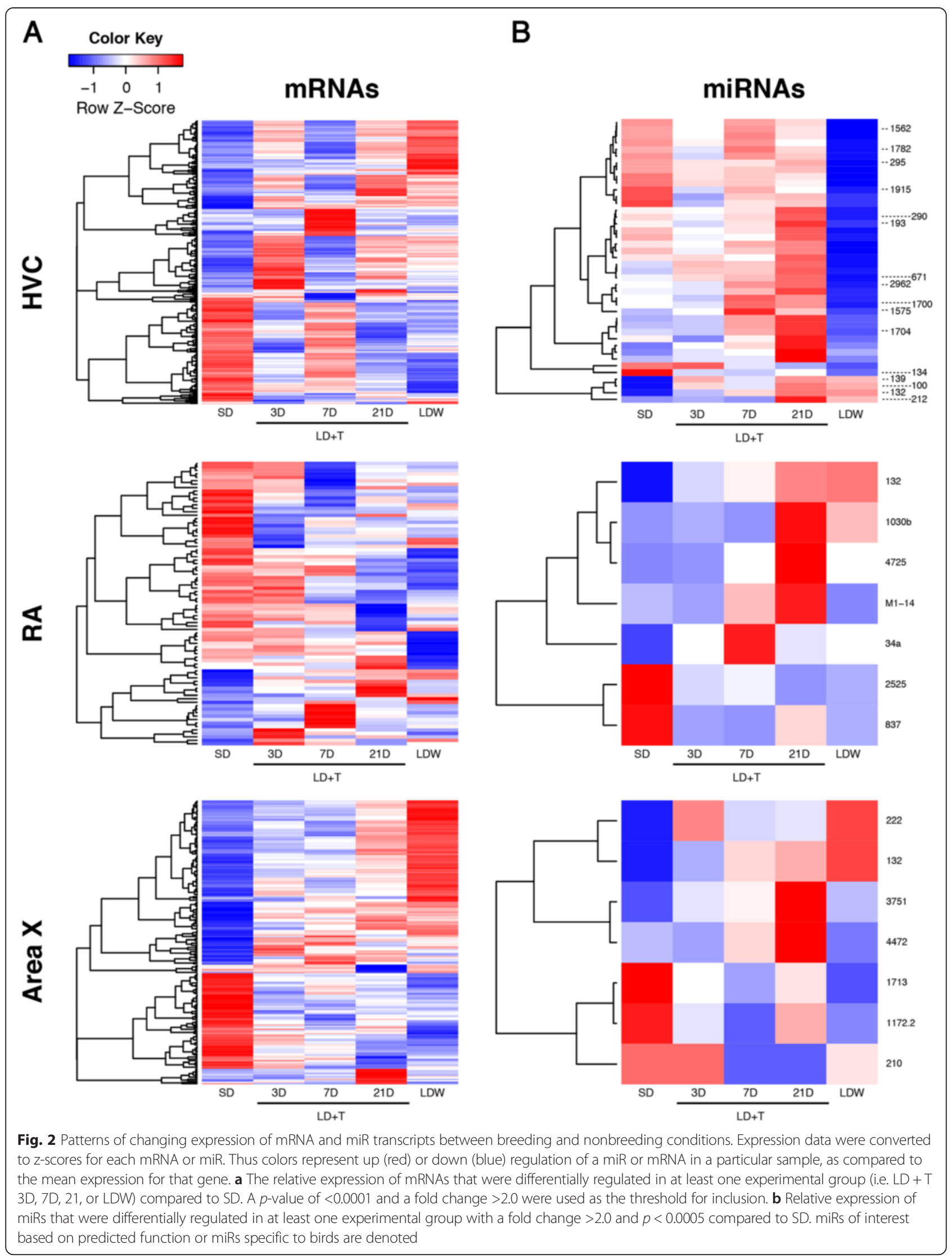


distribution, quantity, and OD260/280 and OD 260/230 ratios of 1.8-2.1 were used for further array analysis. Total RNA samples were used for mRNA and microRNA arrays analysis.

For mRNA analysis, samples were processed and hybridized to Agilent ZebraFinch Oligoarray v2.2 (Agilent, Santa Clara, CA). The Agilent ZebraFinch Oligoarray v2.2 was designed with 43,488 60-mer oligos representing 10,647 annotated genes ([43, 44]). RNA isolation from brain punches resulted in a lower yield than is required for Agilent ZebraFinch Oligoarray v2.2. Therefore, RNA amplification was performed using the Nugen Ovation PicoSL WTA kit according to the manufacturer's protocol. Amplified RNA was used for further processing and hybridization to the Agilent arrays using the manufacturer's established one color protocol. Hybridization and washing of these arrays was accomplished using HS 400 Pro hybridization and wash stations (Tecan Systems, Inc., San Jose, CA). In total 45 microarrays were used, including three replicates for each nucleus from each experimental time point. Arrays were scanned using an Agilent DNA Microarray Scanner (Agilent Technologies, Inc. Santa Clara, CA), according to the manufacturer's established standard protocol.

For miR analysis, samples were processed and hybridized to Affymetrix miRNA 3.0 arrays (Affymetrix, Santa Clara, CA). The Affymetrix miRNA 3.0 array was designed based on the miRBase v17 database. This array contains probe sets for 19,724 mature microRNAs from a total of 153 species including several avian species. Samples isolated form three individual birds belonging to the same experimental groups were pooled. For each experimental group, three biological replicates of pooled samples (i.e., a total of nine birds in three pooled samples) were processed and hybridized to Affymetrix miRNA 3.0 arrays according to the manufacturer's recommended protocol. Arrays were scanned with an Affymetrix GeneChip 3000 scanner. In total 45 microarrays

Table 1 Top canonical pathways of mRNAs seasonally regulated in HVC, RA, and Area X

\begin{tabular}{|c|c|c|c|c|}
\hline & Top Canonical Pathways & $p$-value & Ratio & \# of Genes \\
\hline \multicolumn{5}{|l|}{ HVC } \\
\hline \multirow[t]{2}{*}{$3 \mathrm{D}$} & RAN Signaling & 0.0009 & 0.214 & 3 \\
\hline & Cell Cycle Control & 0.0235 & 0.118 & 2 \\
\hline \multirow[t]{2}{*}{ 7D } & Galactose Degradation & 0.0280 & 0.200 & 1 \\
\hline & UDP-N-acetyl-D-galactosamine Biosynthesis & 0.0057 & 0.143 & 1 \\
\hline \multirow[t]{2}{*}{$21 \mathrm{D}$} & ERK5 Signaling & 0.0001 & 0.103 & 4 \\
\hline & NGF Signaling & 0.0064 & 0.062 & 5 \\
\hline \multirow[t]{2}{*}{ LDW } & ATM Signaling & 0.0168 & 0.075 & 3 \\
\hline & Tumoricidal Function & 0.0171 & 0.133 & 2 \\
\hline \multicolumn{5}{|l|}{ RA } \\
\hline \multirow[t]{2}{*}{$3 \mathrm{D}$} & Wnt/Ca + Pathway & 0.0500 & 0.214 & 1 \\
\hline & Axonal Guidance Signaling & 0.0500 & 0.008 & 2 \\
\hline \multirow[t]{2}{*}{ 7D } & Myo-inositol Signaling & 0.0081 & 0.086 & 3 \\
\hline & T Lymphcyte Signaling & 0.0478 & 0.042 & 1 \\
\hline \multirow[t]{2}{*}{$21 \mathrm{D}$} & Cancer Signaling & 0.0027 & 0.056 & 2 \\
\hline & Synaptic Long Term Depression & 0.0105 & 0.023 & 2 \\
\hline \multirow[t]{2}{*}{ LDW } & Sphingosine Metabolism & 0.0054 & 0.500 & 1 \\
\hline & Ceramide Degradation & 0.0054 & 0.500 & 1 \\
\hline \multicolumn{5}{|c|}{ Area $X$} \\
\hline \multirow[t]{2}{*}{$3 \mathrm{D}$} & Galactose Degradation & 0.0152 & 0.200 & 1 \\
\hline & RAN Signaling & 0.0420 & 0.071 & 1 \\
\hline \multirow[t]{2}{*}{$7 D$} & Flavin Biosynthesis & 0.0029 & 1.000 & 1 \\
\hline & Salvage Pathway & 0.0110 & 0.025 & 1 \\
\hline \multirow[t]{2}{*}{210} & Granulocyte Adhesion & 0.0130 & 0.045 & 2 \\
\hline & Gylcerol Degradation & 0.0197 & 0.200 & 1 \\
\hline \multirow[t]{2}{*}{ LDW } & LPS/ IL-1 Mediated Function & 0.0060 & 0.056 & 5 \\
\hline & MIF-mediated Glucocorticoid Regulation & 0.0100 & 0.167 & 2 \\
\hline
\end{tabular}


were used, including three replicates for each nucleus from each experimental time point. The hybridized arrays were scanned with an Affymetrix GeneChip 3000 scanner.
Microarray data analysis

Raw mRNA array data from the Agilent Zebrafinch Oligoarrays was extracted with the Agilent Feature Extraction image analysis software (Agilent, Santa Clara, CA).

Table 2 Significantly differentially expressed miRNAs with a fold change $>1.5$ and $p<0.0005$

\begin{tabular}{|c|c|c|c|c|c|c|c|c|c|c|c|c|}
\hline & & $3 D$ & & & $7 D$ & & & $21 D$ & & & LDW & \\
\hline \multirow[t]{15}{*}{ HVC } & miRNA & $\begin{array}{l}\text { Fold } \\
\text { Change }\end{array}$ & $p$-value & miRNA & $\begin{array}{l}\text { Fold } \\
\text { Change }\end{array}$ & $p$-value & miRNA & $\begin{array}{l}\text { Fold } \\
\text { Change }\end{array}$ & $p$-value & miRNA & $\begin{array}{l}\text { Fold } \\
\text { Change }\end{array}$ & $p$-value \\
\hline & \multirow[t]{14}{*}{$\operatorname{miR}-132(4)^{\mathrm{a}}$} & \multirow[t]{14}{*}{$1.88 \pm 0.18$} & \multirow[t]{14}{*}{0.0015} & \multirow[t]{14}{*}{ miR-132 (12) } & \multirow[t]{14}{*}{$2.83 \pm 0.06$} & \multirow[t]{14}{*}{0.0033} & $\begin{array}{l}\text { miR-132 } \\
\text { (13) }\end{array}$ & $3.63 \pm 0.07$ & $<0.0001$ & $\begin{array}{l}\text { miR-132 } \\
\text { (13) }\end{array}$ & $3.65 \pm 0.10$ & 0.0001 \\
\hline & & & & & & & miR-1356 & 2.00 & $<0.0001$ & miR-134 & -1.12 & 0.0001 \\
\hline & & & & & & & miR-212 & 1.96 & 0.0001 & miR-1182 & -1.81 & 0.0005 \\
\hline & & & & & & & miR-2840 & 1.69 & 0.0004 & miR-404 & -1.83 & 0.0005 \\
\hline & & & & & & & & & & miR-1915 & -1.98 & 0.0002 \\
\hline & & & & & & & & & & miR-395f & -2.11 & 0.0003 \\
\hline & & & & & & & & & & miR-2455 & -2.23 & 0.0003 \\
\hline & & & & & & & & & & miR-1562 & -2.39 & 0.0002 \\
\hline & & & & & & & & & & miR-4516 & -2.44 & $<0.0001$ \\
\hline & & & & & & & & & & miR-574 & -2.45 & 0.0005 \\
\hline & & & & & & & & & & miR-295 & -2.53 & 0.0004 \\
\hline & & & & & & & & & & miR-395b & -2.57 & 0.0001 \\
\hline & & & & & & & & & & miR-1782 & -2.68 & 0.0004 \\
\hline & & & & & & & & & & miR-1362 & -2.79 & 0.0001 \\
\hline \multicolumn{13}{|l|}{ RA } \\
\hline & miR-281 & 4.47 & 0.0001 & miR-34a & 5.00 & $<0.0001$ & $\begin{array}{l}\operatorname{miR}-132 \\
(4)\end{array}$ & $1.88 \pm 0.05$ & 0.0001 & $\begin{array}{l}\text { miR-132 } \\
(4)\end{array}$ & $1.90 \pm 0.11$ & 0.0001 \\
\hline & miR-1192 & 3.98 & 0.0003 & miR-2111n & 4.84 & $<0.0001$ & miR-2525 & -2.40 & 0.0004 & & & \\
\hline & miR-184 & 3.94 & 0.0004 & miR-2571 & 4.47 & 0.0001 & & & & & & \\
\hline & miR-77 & 3.86 & 0.0005 & miR-311b & 4.29 & 0.0001 & & & & & & \\
\hline & miR-4197 & -3.92 & 0.0004 & miR-4142 & 4.02 & 0.0003 & & & & & & \\
\hline & miR-236 & -3.94 & 0.0004 & mir-135a & 3.98 & 0.0003 & & & & & & \\
\hline & miR-2182 & -4.03 & 0.0003 & miR-8 & 3.97 & 0.0003 & & & & & & \\
\hline & miR-758 & -4.04 & 0.0003 & miR-199b & 3.85 & 0.0005 & & & & & & \\
\hline & miR-982 & -4.33 & 0.0001 & miR-837 & -3.90 & 0.0004 & & & & & & \\
\hline & miR-34 & -4.62 & 0.0001 & miR-528 & -4.03 & 0.0003 & & & & & & \\
\hline & mir-4478 & -4.73 & $<0.0001$ & miR-441a & -4.15 & 0.0002 & & & & & & \\
\hline & \multirow[t]{5}{*}{ miR-3479 } & \multirow[t]{5}{*}{-5.23} & \multirow[t]{5}{*}{$<0.0001$} & miR-395 g & -4.17 & 0.0002 & & & & & & \\
\hline & & & & mir-23a & -4.22 & 0.0002 & & & & & & \\
\hline & & & & miR-2357 & -4.23 & 0.0002 & & & & & & \\
\hline & & & & mir-3673 & -4.35 & 0.0001 & & & & & & \\
\hline & & & & mir-129 & -4.64 & $<0.0001$ & & & & & & \\
\hline \multicolumn{13}{|c|}{ Area X } \\
\hline & miR-2491 & 2.00 & 0.0002 & miR-210 & -1.96 & $<0.0001$ & miR-3751 & 1.35 & $<0.0001$ & $\begin{array}{l}\operatorname{miR}-132 \\
(6)\end{array}$ & $1.69 \pm 0.06$ & 0.0002 \\
\hline & miR-132 (2) & $\begin{array}{l}-1.79 \pm \\
0.16\end{array}$ & 0.0002 & & & & $\begin{array}{l}\text { miR-210 } \\
\text { (4) }\end{array}$ & $\begin{array}{l}-1.71 \pm \\
0.09\end{array}$ & 0.0003 & miR-1713 & -1.55 & $<0.0001$ \\
\hline
\end{tabular}


The data were normalized using a variance-stabilization procedure (VSN) [45]. Image generation and feature extraction for Affymetrix microRNA 3.0 arrays was performed using Affymetrix GeneChip Command Console Software. The raw microRNA array data was normalized using quantile normalization, followed by a robust multi-array average (RMA; [46]) with Bioconductor [47]. Several quality control steps were followed: (1) visual inspection of the GCOS chip images, (2) visual inspection of the chip pseudoimages generated by the Bioconductor affyPLM package, (3) generation and inspection of principal components analysis (PCA) plots, (4) generation and inspection of histograms of raw signal intensities, and (5) generation and comparison of the Relative Log Expression and Normalized Unscaled Standard Errors using the Bioconductor affyPLM package. MiRs and mRNAs with significant differential expression were identified using the Bioconductor limma package [48]. Data were analyzed using a weighted analysis of variance (ANOVA) model, making individual comparisons using empirical Bayes adjusted contrasts. The weighted ANOVA model assigned array weights to smoothly up or down-weight the importance of a particular array, based on how similar that array is to others of the same type [49]. The empirical Bayes adjustment estimates a variance prior based on all genes or miRNAs on the array, and then reduces the by-gene estimates towards that prior [48].

We compared the differentially expressed mRNAs from our study to previously published gene expression data sets ([40, 44]; GSE28347 and GSE33365, respectively) using $\mathrm{R}$ software (http://www.r-project.org/). We filtered both gene expression data sets for differentially expressed genes using the published filtering criteria used in the prior studies (i.e. a threshold of 1.5-fold change and $p<0.05$ for the Thompson et al. (2012) data, and a 2-fold change and $p<0.01$ for Whitney et al. (2014); [40, 44]). Prior to making comparisons we assigned HUGO Gene Nomenclature Committee symbols (http://www.genenames.org) to the probes. This resulted in a $75 \%$ overlap in gene symbols between our array targets and the targets of the arrays used in Thomspon et al. (2012). Whitney et al. (2014) utilized the same array platform as we did. We compared the differentially expressed genes in HVC, RA, and Area X in $\mathrm{LD}+\mathrm{T} 3,7$, and 21D and LDW relative to SD across our and the Thompson et al. (2012) datasets. We compared our results from $\mathrm{LD}+\mathrm{T} 21 \mathrm{D}$ relative to $\mathrm{SD}$ to the

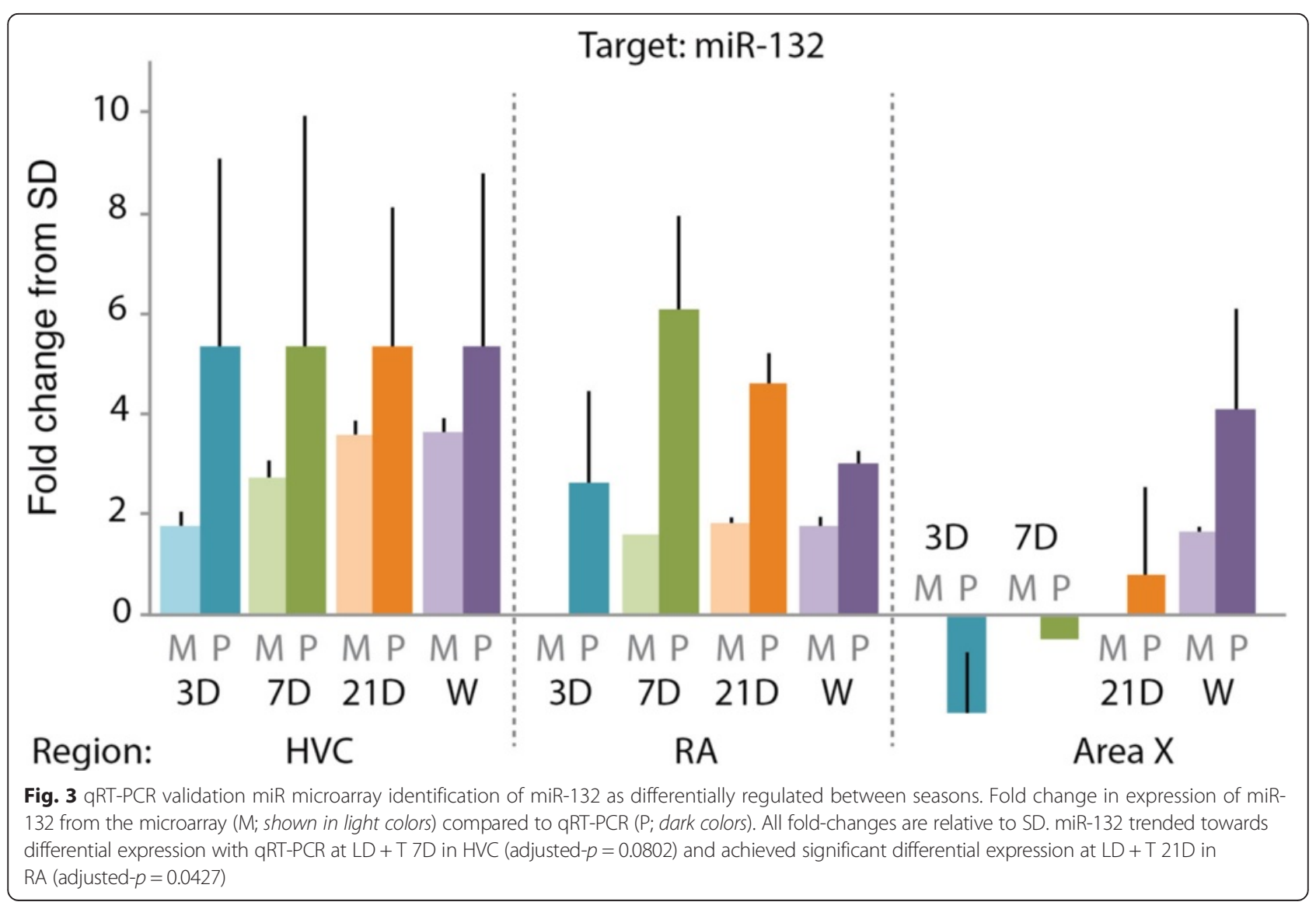




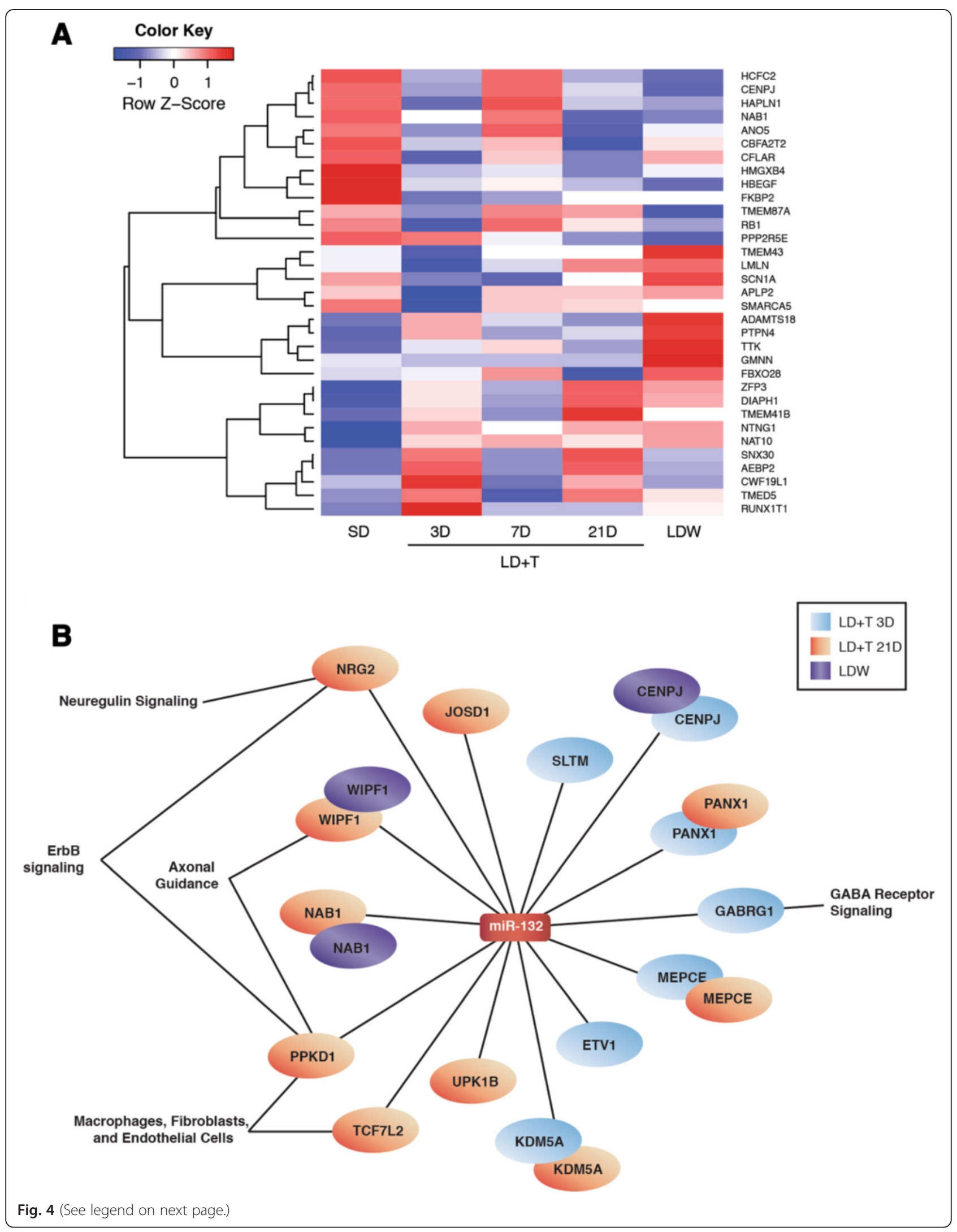


(See figure on previous page.)

Fig. 4 The seasonal miR-132-mRNA regulatory network in HVC. a The relative expression changes of mRNA targets of miR-132 that were differentially regulated in at least one experimental group (i.e. LD + T 3D, 21, or LDW) compared to SD, as well as having an inverse correlation to miR-132 in the same comparison. A $p$-value of $<0.005$ and a fold change $>1.5$ at any time point were used as selection criteria for mRNAs presented in the heat map. $\mathbf{b}$ An interaction network of mRNAs that were differentially anti-expressed with a fold change $>-1.5$ and $p<0.005$ from conditions in which miR-132 was also differentially expressed (i.e. fold change $>$ 2.0). IPA network analyses revealed several key pathways were down-regulated during periods of HVC new neuronal addition and functional incorporation

differentially expressed genes between $5 \mathrm{~h}$ of singing and no singing of Whitney et al. (2014).

Real-time quantitative PCR confirmation of miR expression Differentially expressed genes of interest were selected for internal validation of the microarray results by TaqMan based real-time quantitative reverse transcription (qRT-PCR). The goal of the qRT-PCR was to confirm the identity and expression of genes shown by the microarray analysis to be differentially expressed. Four micro-liters of remaining cRNA not used for microarray hybridization was added to each $25 \mu \mathrm{l} \mathrm{PCR}$ mixture consisting of primers $(0.16 \mu \mathrm{M}$ each) specific to one miR of interest, buffers, salts, and SYBR Green PCR master mix. Fluorescence detection was measured using the 7900HT FAST RealTime PCR System (Applied Biosystems, Foster City, CA) with the following PCR reaction profile: 1 cycle of $95{ }^{\circ} \mathrm{C}$ for $10 \mathrm{~min}, 40$ cycles of $95{ }^{\circ} \mathrm{C}$ for $30 \mathrm{~s}$, and $60{ }^{\circ} \mathrm{C}$ for $60 \mathrm{~s}$, followed by a melt curve. DNA amplification was quantified from the $C(T)$ value based on standard curves to ensure quantification was within a linear range. All signals were normalized against U6, and fold-change ratios were calculated for experimental samples compared to SD controls using $\mathrm{R}$ software. miR-132 qRT-PCR expression across nuclei at

Table 3 Top pathways for miR-132 and miR-210 predicted mRNA targets across all time points

\begin{tabular}{|c|c|c|c|c|}
\hline $\begin{array}{l}\text { Top Canonical } \\
\text { Pathway }\end{array}$ & & $p$-value & Ratio & Genes \\
\hline \multicolumn{5}{|l|}{ miR-132 HVC } \\
\hline & Molecular Mechanisms of Cancer & $<0.0001$ & 0.0301 & $\begin{array}{l}\text { E2F5, CFLAR, ADCY3, ARHGEF10, CDKN1A, MAPK1, TGFB2, PRKD1, } \\
\text { RAP2B, PRKAG2, FOXO1 }\end{array}$ \\
\hline & RAR Activation & 0.0001 & 0.0398 & ADCY3, MAPK1, TGFB2, PRKD1, PRKAG2, NCOR1, GTF2H1 \\
\hline & VDR/RXR Activation & 0.0001 & 0.0641 & CDKN1A, TGFB2, PRKD1, NCOR1, FOXO1 \\
\hline & Breast Cancer Regulation by Stathmin 1 & 0.0001 & 0.0366 & E2F5, ADCY3, ARHGEF10, CDKN1A, MAPK1, PRKD1, PRKAG2 \\
\hline & ErbB Signaling & 0.0001 & 0.0581 & HBEGF, MAPK1, PRKD1, NRG2, FOXO1 \\
\hline & Pancreatic Adenocarcinoma Signaling & 0.0003 & 0.0472 & E2F5, HBEGF, CDKN1A, MAPK1, TGFB2 \\
\hline & Cell Cycle: G1/S Checkpoint Regulation & 0.0005 & 0.0625 & E2F5, CDKN1A, TGFB2, FOXO1 \\
\hline & PPARa/RXRa Activation & 0.0005 & 0.0335 & ADCY3, MAPK1, TGFB2, CAND1, PRKAG2, NCOR1 \\
\hline & Leptin Signaling & 0.0008 & 0.0541 & ADCY3, MAPK1, PRKAG2, FOXO1 \\
\hline & Acute Myeloid Leukemia Signaling & 0.0009 & 0.0519 & KITLG, MAPK1, TCF7L2, TCF7L1 \\
\hline \multicolumn{5}{|l|}{ miR-210 Area $X$} \\
\hline & Phospholipase C Signaling & 0.0022 & 0.0126 & ADCY5, BTK, PPP1CB \\
\hline & Dopamine Receptor Signaling & 0.0033 & 0.0256 & ADCY5, PPP1CB \\
\hline & CDK5 Signaling & 0.0052 & 0.0202 & $\mathrm{ADCY} 5, \mathrm{PPP} 1 \mathrm{CB}$ \\
\hline & NAD Biosynthesis III & 0.0066 & 0.1670 & NMNAT2 \\
\hline & Phosphatidylcholine Biosynthesis I & 0.0078 & 0.1430 & PCYT1B \\
\hline & NAD Salvage Pathway III & 0.0078 & 0.1430 & NMNAT2 \\
\hline & Cellular Effects of Sildenafil (Viagra) & 0.0089 & 0.0155 & ADCY5, PPP1CB \\
\hline & $\beta$-adrenergic Signaling & 0.0093 & 0.0150 & ADCY5, PPP1CB \\
\hline & Calcium Transport I & 0.0100 & 0.1110 & ATP2B3 \\
\hline & $\begin{array}{l}\text { Dopamine-DARPP32 Feedback in } \\
\text { CAMP Signaling }\end{array}$ & 0.0135 & 0.0124 & ADCY5, PPP1CB \\
\hline
\end{tabular}


Table 4 Top pathways for miR-132 in HVC predicted mRNA targets at each time point

\begin{tabular}{|c|c|c|c|c|}
\hline Top Canonical Pathways & & $p$-Value & Ratio & \# Genes \\
\hline \multicolumn{5}{|l|}{$L D+T 3 D$} \\
\hline & Breast Cancer Regulation & 0.0017 & 0.0209 & 4 \\
\hline & Estrogen-mediated S-phase Entry & 0.0019 & 0.0833 & 2 \\
\hline & Molecular Mechanisms of Cancer & 0.0028 & 0.0137 & 5 \\
\hline & Cell Cycle Checkpoint Control & 0.0094 & 0.0364 & 2 \\
\hline & Wnt/ß-catenin Sginaling & 0.0103 & 0.0178 & 3 \\
\hline \multicolumn{5}{|l|}{$L D+T 7 D$} \\
\hline & PTEN Signaling & 0.0009 & 0.0254 & 3 \\
\hline & AMPK Signaling & 0.0013 & 0.0224 & 3 \\
\hline & Melanoma Signaling & 0.0030 & 0.0476 & 2 \\
\hline & Calcium Signaling & 0.0029 & 0.0169 & 3 \\
\hline & Antiproliferative Role & 0.0046 & 0.0317 & 2 \\
\hline \multicolumn{5}{|l|}{$L D+T 21 D$} \\
\hline & ErbB Signaling & $<0.0001$ & 0.0581 & 5 \\
\hline & Neuregulin Signaling & 0.0001 & 0.0455 & 4 \\
\hline & ErbB2/3 Signaling & 0.0006 & 0.0526 & 3 \\
\hline & Molecular Mechanisms of Cancer & 0.0006 & 0.0164 & 6 \\
\hline & ErbB4 Signaling & 0.0007 & 0.0500 & 3 \\
\hline \multicolumn{5}{|l|}{ LDW } \\
\hline & Melanocyte Development, Pigmentation Signaling & 0.0001 & 0.0357 & 3 \\
\hline & CDK5 Signaling & 0.0002 & 0.0303 & 3 \\
\hline & RAR Activation & 0.0009 & 0.0170 & 3 \\
\hline & PPARa/RXRa Activation & 0.0010 & 0.0168 & 3 \\
\hline & Pyridoxal 5'-phosphate Salvage Pathway & 0.0023 & 0.0313 & 2 \\
\hline
\end{tabular}

$\mathrm{LD}+\mathrm{T} 3 \mathrm{D}, 7 \mathrm{D}, 21 \mathrm{D}$, and $\mathrm{LDW}$ relative to $\mathrm{SD}$ were fit with ANOVA and had p-values adjusted using a family-wise error rate (FWER) adjustment and subsequent Hommel correction for multiple comparison.

\section{MiR sequencing and analysis}

In order to cross correlate seasonally regulated mRNAs to the differentially regulated miRs, we used the microRNA Target Filter function of the Ingenuity Pathway Analysis software (IPA, http://www.ingenuity.com) as described below. The miR sequence, specifically the mature and seed region sequences, were confirmed to be $100 \%$ homologous to the equivalent human miR. Briefly, primers for PCR were designed to amplify the full sequence of Gambel's white-crowned sparrow miRs of interest using the sequence of that miR in closely related bird species and a broad range of vertebrates. From genomic DNA, full genomic miR sequences were amplified with PCR using Quick Load Master Mix (New England Biolabs) as per the manufacturer's protocol. MiR sequence was verified (via GeneWiz, Seattle, WA) from independent PCR product of five individual birds after isolation from a $1.5 \%$ electrophoresis gel using the
Qiagen Gel Extraction Kit. All miRs of interest were confirmed to have $100 \%$ identity within the mature and seed regions of human and mouse sequences (Additional file 1: Table S1). For miR-132 and miR-210, rooted phylogenetic trees with branch lengths were constructed in ClustalW (www.genome.jp/tools/clustalw/) using the white-crowned sparrow sequence and the respective miR sequences of other vertebrates obtained through the miRBase, v17 database (mirbase.org, University of Manchester) or when not available, as with miR-210, annotated sequences from bird (taxid:8782) BLAST hits (blast.ncbi.nlm.nih.gov; Additional file 2: Figures S1 and Additional file 3: Figure S2).

\section{Canonical signaling pathway and miR target predictions}

Conserved canonical signaling pathways were predicted for both mRNAs and miRs using the core analysis module of the IPA software (Ingenuity, http://www.ingenuity.com). Canonical pathways with $p<0.05$ were considered significant. Potential targets of miR-132 and miR-210 were predicted using the miR Target Filter module in IPA (Ingenuity) and applying the filtering criteria moderate or high confidence based on the 


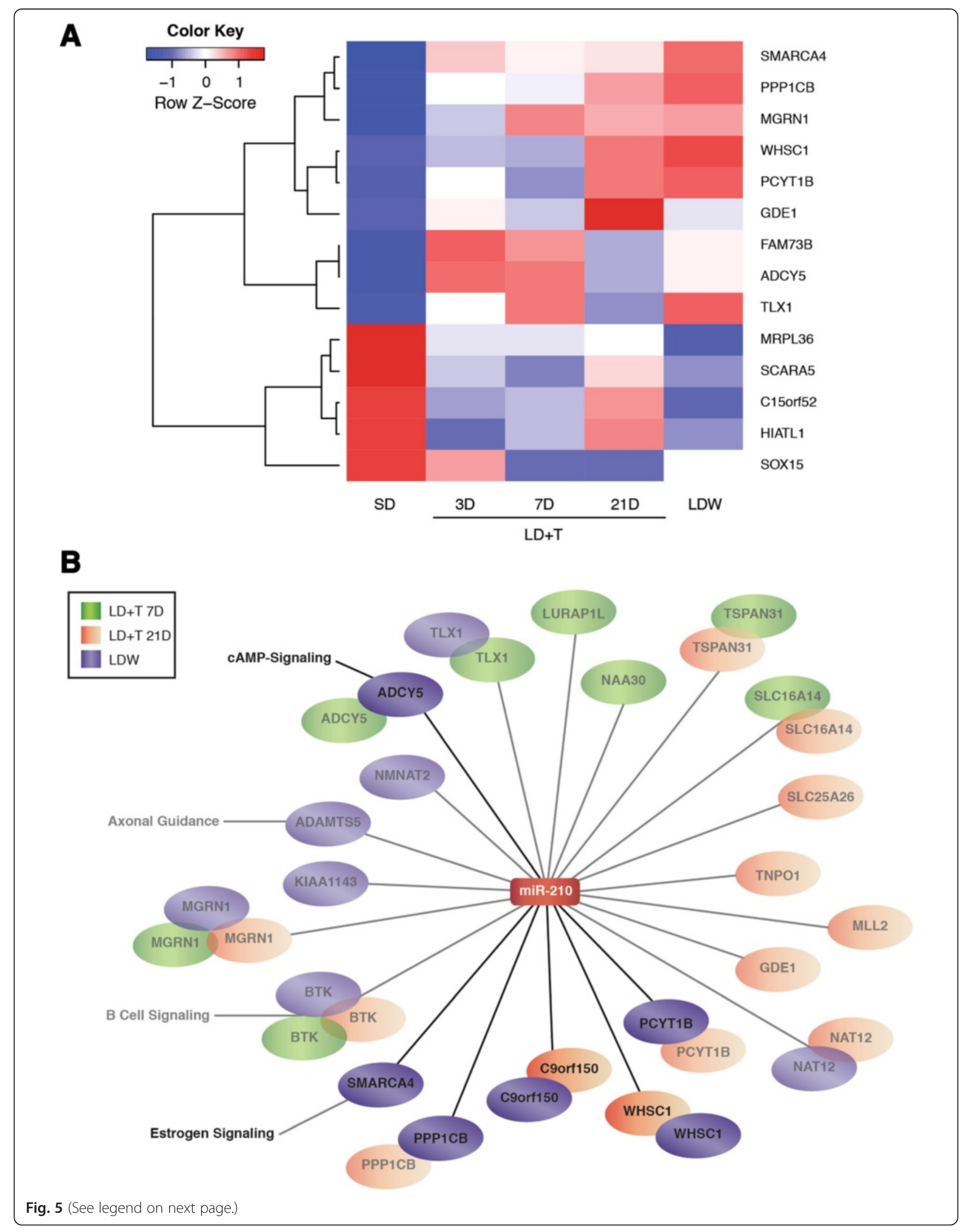


(See figure on previous page.)

Fig. 5 The seasonal miR-210 -mRNA regulatory network in HVC. a The expression fold changes of miR-210 mRNA that were differentially regulated and inversely correlated in at least one experimental group in which miR-210 was also differentially expressed (i.e. LD + T 7D, 21, or LDW) compared to SD. A $p$-value of $<0.005$ and fold change $>1.5$ at any time point were used as selection criteria for mRNAs presented in the heat map. $\mathbf{b}$ An interaction network of mRNAs that were differentially anti-expressed with a fold change $>1.5$ and $p<0.005$ (bright) or $p<0.05$ (faded) from conditions in which miR-210 was also differentially expressed (i.e. fold change $>-2.0$ ). IPA network analyses revealed several key pathways were up-regulated in Area $X$ during periods of volume expansion

TargetScan database, as well as experimentally validated targets based on the miRBase and miRecords databases. It is important to recognize that the IPA data base contains mRNA sequence information from mouse, rat, and human, but not white-crowned sparrow or other avian species. Therefore, the IPA predicted microRNA targets are based on these mammalian mRNA sequences. Currently a white-crowned sparrow data base is not available to identify predicted targets of microRNAs. We used the following approach to minimize the chance of drawing conclusions based on incorrectly predicted targets. First, we performed pathway analyses with two miRs - miR-132 and miR-210-both of which have $100 \%$ identity in white-crowned sparrows with the respective human miR sequence. Second, we overlaid and filtered all miR targets with the white-crowned sparrow mRNA array data generated using the same samples with the IPA predicted targets. We only used those predicted mRNA targets that were also inversely differentially expressed $(>1.5$-fold, $p<0.005)$ in our white-crowned sparrow mRNA array data for further analysis. Third, we focused our analysis on identified pathways suggested by
microRNA targets, thereby minimizing the potential pitfall of placing too much emphasis on single target genes.

\section{Results and discussion}

Seasonal expression of mRNAs in the song control nuclei We identified differential expression of mRNA between breeding and nonbreeding condition using microarray analyses of tissue harvested from HVC, RA, and Area X, in SD, LD + T at 3D, 7D, 21D, and LDW conditions. We obtained 155, 61, 43, and 67 of differentially expressed (fold $>2.0, p<0.0001$ ) mRNAs in HVC at LD $+\mathrm{T} 3 \mathrm{D}$, 7D, 21D, and LDW, respectively (Fig. 2a; Additional file 4: Table S2). In RA 7, 14, 10, and 10 and in Area X 21, 25,29 , and 81 genes varied by $>2.0$ fold change with $p<0.0001$ in $\mathrm{LD}+\mathrm{T} 3 \mathrm{D}, 7 \mathrm{D}, 21 \mathrm{D}$, and LDW, respectively (Fig. 2a; Additional file 4: Table S2). We found in the neurogenic nuclei HVC and Area X that only 8.6-13.9\% and 31.0-41.9\%, respectively, of the genes that were differentially expressed across all time points were down regulated (Fig. 2a; Additional file 4: Table S2). In the non-neurogenic nucleus RA we found a higher percentage of genes down-regulated

Table 5 Top pathways for miR-210 in Area X predicted mRNA targets at each time point

\begin{tabular}{|c|c|c|c|c|}
\hline Top Canonical Pathways & & $p$-Value & Ratio & \# Genes \\
\hline \multicolumn{5}{|l|}{$L D+T 7 D$} \\
\hline & Phospholipase C Signaling & 0.0049 & 0.0084 & 2 \\
\hline & B Lymphocyte Signaling & 0.0184 & 0.0244 & 1 \\
\hline & Serotonin Receptor Signaling & 0.0197 & 0.0227 & 1 \\
\hline & Primary Immunodeficiency Signaling & 0.0232 & 0.0192 & 1 \\
\hline & GABA Receptor Signaling & 0.0299 & 0.0149 & 1 \\
\hline \multicolumn{5}{|l|}{$L D+T 21 D$} \\
\hline & Phosphatidylcholine Biosynthesis & 0.0039 & 0.1430 & 1 \\
\hline & Calcium Transport I & 0.0050 & 0.1110 & 1 \\
\hline & Choline Biosynthesis III & 0.0071 & 0.0769 & 1 \\
\hline & RAN Signaling & 0.0093 & 0.0588 & 1 \\
\hline & Chemokine Signaling & 0.0389 & 0.0141 & 1 \\
\hline \multicolumn{5}{|l|}{ LDW } \\
\hline & Phospholipase C Signaling & 0.0007 & 0.0126 & 3 \\
\hline & Dopamine Receptor Signaling & 0.0015 & 0.0256 & 2 \\
\hline & CDK5 Signaling & 0.0025 & 0.0202 & 2 \\
\hline & Cellular Effects of Sildenafil & 0.0042 & 0.0155 & 2 \\
\hline & Cardiac $\beta$-adrenergic Signaling & 0.0044 & 0.0150 & 2 \\
\hline
\end{tabular}


and greater variability in this percentage across experimental groups compared to the neurogenic nuclei; the percentage of down regulated genes in RA varied from 50 to $97 \%$ across all time points. We used IPA to identify significant pathways in our data. Seasonally regulated mRNAs were involved in several canonical signaling pathways including ERK5 and NGF signaling in $\mathrm{HVC}$ and $\mathrm{WNT} / \mathrm{Ca}+$ and axonal guidance signaling in RA (Table 1). Upon transition from breeding to nonbreeding conditions (LDW group), we found that genes in the canonical signaling pathways for cell death (i.e. tumorcidal) and inflammation (i.e. LPS/IL1) were differentially expressed compared to $S D$ in HVC and Area X (Table 1).

Gene regulatory networks that control patterning and plasticity within song control nuclei have been previously examined with sequencing analysis of the zebra finch genome as well as microarray analysis [43, 50]. More specifically, Thompson et al. (2012) identified 132 genes in HVC cells that changed in expression between breeding and nonbreeding conditions when compared to gene expression in RA, a non-neurogenic region of the song bird brain [40]. By comparison, we identified 265 genes differentially expressed between $\mathrm{HVC}$ and RA in breeding conditions and 239 in nonbreeding conditions. In both studies, genes that promoted proliferation, angiogenesis, and neurite extension were upregulated, whereas genes that support programmed cell death were down-regulated in HVC under breeding conditions [40]. Specific genes that encode neurotrophins known to promote neuronal migration, recruitment, and survival, including brain-derived neurotrophic factor $(B D N F)$ and insulin-like growth factor 1 were differentially regulated in HVC under breeding conditions in both studies [40]. A detailed comparison of specific genes differentially regulated in both the current study and the data from Thompson et al. (2012) revealed that neuropeptide $Y(N P Y)$ was differentially expressed in HVC during LD + T 21D. No other genes were commonly shared as significantly differentially regulated across brain regions and across common experimental groups. This comparison was limited, however, by a $27 \%$ concordance for clone IDs and $75 \%$ concordance for gene symbols between the two array platforms used within these studies [40].

During breeding conditions, the period in which HVC incorporates a significant number or adult-born neurons, white-crowned sparrows sing with greater stereotypy and more often when compared to both SD and LDW [35, 37]. Previous studies have examined differential gene expression related specifically to singing behavior in zebra finches $[44,51]$. For example, Whitney et al. (2014) identified 5167 differentially expressed transcripts in HVC, RA, Area X and LMAN that grouped into four superclusters of transient early and late-response increases and decreases. Examination of enriched gene pathways in both our study and Whitney et al. (2014) identified pathways related to MEF/ERK signaling in HVC, Wnt signaling in RA, and biogenesis in Area X [44]. Direct comparison of the differentially expressed genes in the $\mathrm{LD}+\mathrm{T} 21 \mathrm{D}$ group of the white-crowned sparrows with those of zebra finches singing for $5 \mathrm{~h}$ versus no singing resulted in only one shared differentially expressed gene - ASAP3 in Area X.

\section{miRs are differentially expressed in song control nuclei between breeding and nonbreeding conditions}

To test whether miRs were differentially expressed between breeding and nonbreeding conditions, we quantified with microarray the fold-change relative to SD of over 150 unique miRs in tissue from HVC, RA and Area $\mathrm{X}$ of birds in $\mathrm{LD}+\mathrm{T}$ and LDW. Of the three miRs that were significantly differentially expressed across all conditions $(>2.0$ fold change and false discovery rate $=0.05$ ), miR-132, specifically within HVC, exhibited the highest fold change in expression (Additional file 5: Table S3). Using a less stringent threshold of fold change $>2.0$ and $p<0.0005$, we obtained $4,13,19$, and 29 differentially expressed miRs in $\mathrm{HVC}$, at $\mathrm{LD}+\mathrm{T}$ 3D, 7D, 21D, and LDW, respectively (Table 2 and Fig. 2b). In RA we found thirty miRs that were differentially expressed in one or more experimental groups, whereas in Area $\mathrm{X}$ only five miRs were differentially expressed with the fold change $>2.0$ and $p<0.0005$ (Table 2 and Fig. 2b). The expression landscapes in HVC, RA, and Area X suggest that the majority of miRs are generally upregulated with time into breeding condition (Fig. 2b). Concomitantly, large clusters of mRNAs became down-regulated with progression into breeding condition in all three nuclei (Fig. 2a). Alternatively, during LDW 13 miRs in HVC decreased significantly in expression compared to $\mathrm{SD}$, while large clusters of mRNAs related to macrophage function (e.g. MPEG1), cell arrest (e.g. ZAR1), and sirtuin signaling (e.g. SIRT3) increased in expression.

qRT-PCR of miR-132 on the same tissue used in the miR microarray validated the differential expression of miR-132 from the microarray analyses. The directional trends for miR-132 showed consistent up-regulation in qRT-PCR expression across all experimental groups for which miR-132 was significantly up-regulated in the microarray analyses (Fig. 3). Following FWER adjustment and Hommel correction for multiple comparisons, the differential miR-132 expression at $\mathrm{LD}+\mathrm{T} 21 \mathrm{D}$ in RA achieved significance (adjusted- $p=0.0427$ ).

Previous Illumina sequencing of auditory regions in zebra finches in response to song exposure identified 
121 miRs conserved in other vertebrates and 34 novel miR sequences specific to zebra finches [52]. Consistent with this previous work we found that both conserved and bird-specific miRs were differentially expressed across seasons in the song control circuit. Some of the bird-specific miRs differentially expressed in HVC included miR-1562, -1782, -1915, -2962, -1700, -1575, and -1704 (Fig. $2 \mathrm{~b}$ and Table 2).

Of the highly conserved miRs identified in this study, several are known to play roles in neural plasticity. For example, in the non-neurogenic nucleus RA, we found high expression of miR-135. Previous studies found that miR-135 inhibits the expression of the serotonin transporter and the inhibitory serotonin receptor, thereby promoting an increase in serotonin signaling [53]. The up-regulation of miR-135 in RA coincides with increases in spontaneous firing activity [38] and the probable increased serotonin signaling in RA $[54,55]$. Another miR of interest up-regulated in RA during breeding conditions is miR-184. miR-184 regulates the translation of $N U M B$ [51], a protein necessary for the survival of neural progenitor cells [56], a protein necessary for the survival of neural progenitor cells [57] and neuronal differentiation in the mammalian cortex [58]. miR-184 may confer low levels of NUMB in RA and prevent local neurogenesis. Finally, miR-129, down-regulated in RA during breeding conditions, has previously been shown to inhibit FOXP2 translation [59], a protein thought to be associated with human speech [60], vocal learning in songbirds [61], and neurite outgrowth [62]. FOXP2 has been found to be post-transcriptionally modified by miR-9 and miR-140, both of which are differentially expressed in zebra finch as a result of different social contexts for singing (i.e. directed towards a female or undirected) [63]. Moreover, the identification of avian gene targets of FOXP2 through co-expression network analyses [51] suggests that FOXP2 itself serves as a fulcrum for coordinating large regulatory gene networks. Given these previous findings and that miR-129, a predicted regulator of FOXP2, is differentially expressed across seasons in RA, the occurrence and importance of post-transcriptional regulation of FOXP2 is of interest for additional exploration into regulatory networks related to song leaning and neural circuit plasticity.

In the neurogenic nucleus HVC, in addition miR-132, miR-212 expression also increased at 21D into $\mathrm{LD}+\mathrm{T}$. miR-212 transcription occurs at the miR-212/132 cluster [64]. Beyond functioning in tandem with miR-132, which will be discussed in greater detail below, miR-212 has also been shown to independently decrease glial cell proliferation [65]. Moreover, miR-212 expression in the rat dentate gyrus was increased following both acute and chronic electroconvulsive therapy [66], a therapy which increases neural stem cell proliferation [67] and increased neuronal fate specification [68]. Previous reports together with our data suggest that miR-212 functions both in tandem with miR-132 and independently to increase adult neurogenesis.

In HVC upon transition from $\mathrm{LD}+\mathrm{T}$ to $\mathrm{LDW}$, we found two miRs of interest that decreased in expression: miR-295 and miR-134. During LDW cell death peaks as HVC volume collapses [33] and neural stem cell proliferation increases significantly [35]. The timing of decreased miR-295 expression is consistent with a previous report that showed miR-295 suppressed autophagic cell death [69]: miR-295 down-regulation in HVC during LDW may permit the concurrent increase in HVC cell death. Additionally, we found that mir-134 expression was decreased in LDW compared to SD. miR-134 has been shown to regulate neural stem cell proliferation and neural plasticity, however, in a direction seemingly contradictory to our results. Decreased levels of miR-134 have been reported to increase synaptic plasticity and memory formation [70], dendritic spine formation and synaptic maturation [65], and neuronal survival [71]. The signaling mechanisms by which miR-134 exerts these effects, however, are just beginning to be elucidated.

\section{The seasonal interaction network of miR-132 in HVC}

miR-132 mediates the integration of adult-born neurons in dentate gyrus [24], the arborization of new neurons in the hippocampus [23], and radial migration of neurons via expression of FOXP2 [72]. Based on the previously documented role of miR-132 in mammalian adult neurogenesis and synaptic formation and plasticity, and the fact that miR-132 was the most significantly upregulated miR in $\mathrm{HVC}$, we examined the miR-mRNA regulatory network of miR-132 more thoroughly. Prior to such analyses we first confirmed that the sequence of white-crowned sparrow miR-132 (i.e. zlg-mir-132) mature and seed regions was the same as the human miR132 (hsa-mir-132) sequence (Additional file 1: Table S1 and Additional file 2: Figure S1). One-hundred percent identity is necessary because IPA software predicts targets based on the human miR seed region and mRNA $3^{\prime}$ UTR sequences. The zlg-mir-132 sequence was indeed $100 \%$ identical to hsa-mir-132 in both the seed regions and the mature sequence. The full sequence of zlg-mir132 was $62 \%$ identical to the full sequence of hsa-mir132 (miRBase MI0000449), $64 \%$ to rno-mir-132 (rat; miRBase MI0000905), and $96 \%$ to tgu-mir-132 (zebra finch; miRBase MI0016249). Generating a rooted phylogenetic tree with various vertebrate miR-132 sequences represented, grouped the zlg-miR-132 sequence with tgumir-132, further confirming correct full white-crowned sparrow sequence (Additional File 2: Figure S1).

Through IPA software, miR-132 was predicted to target a total of 767 mRNAs. Thirty-three out of the 767 
predicted mRNA targets were differentially expressed $(>1.5$ fold, $p<0.005)$ with expression inversely correlated with miR-132 between breeding and nonbreeding conditions in HVC (Fig. 4a). Of the thirty-three miR-132 targets eleven, two, fourteen, and five targets were differentially expressed during $\mathrm{LD}+\mathrm{T}$ at $3 \mathrm{D}, 7 \mathrm{D}, 21 \mathrm{D}$, and $\mathrm{LDW}$, respectively (Fig. 4a). All of the predicted 33 seasonally-expressed targets of miR-132 were investigated for functional relatedness using IPA, from which we obtained the top significant canonical pathways represented by the filtered targets across all experimental groups (Table 3 and Fig. 4b). Independent analyses of functional relatedness of miR-132 targets from $\mathrm{LD}+\mathrm{T} 3 \mathrm{D}, 7 \mathrm{D}, 21 \mathrm{D}$, and $\mathrm{LDW}$ identified top canonical pathways including cell cycle control, PTEN signaling, calcium signaling, neuregulin signaling, and retinoic acid signaling (Table 4 and Fig. 4b).

High levels of miR-132 expression in HVC are consistent with previous reports of high miR-132 expression in the brains of zebra finches [73]. Moreover, high expression of miR-132 in breeding condition HVC corroborates previous studies on the interactions between this miR, neurotrophins, and the ERK/MAPK signaling cascade. Transcription of miR-132 is controlled directly by the transcription factor cAMP-response element binding protein (CREB; [64]). Activation of CREB by phosphorylation occurs with BDNF binding the TRKB receptor [74], circadian gene oscillation [75], and synaptic activity via nuclear calcium signaling [76]. Activated CREB in combination with BDNF-mediated activation of the ERK/MAPK pathway in turn increases expression of miR-132 [77]. In HVC during breeding conditions, BDNF expression is enhanced by the presence of sex steroids [78] via the expansion of vasculature endothelial cells [79]. Concomitantly, CREB is co-expressed seasonally in HVC with androgen receptors [80], which transactivate CREB when $\mathrm{T}$ binds [81]. Thus, in breeding conditions high $\mathrm{T}$ levels likely promote miR-132 expression via the enhanced activation of CREB and the production and signaling of BDNF in HVC. In turn, miR-132 represses the translation of a variety of repressor genes to promote cell cycle entry [82], neuronal addition [24], and arborization [23], and even the proliferation of endothelial cells [83] that secrete BDNF [79]. In this manner, mir-132 likely supports increased new neuronal addition and survival in HVC during breeding conditions.

The increase of miR-132 during breeding conditions driving a putative increase in BDNF, which in turn promotes HVC neuronal addition, is also consistent with previous studies. In both juvenile and adult birds, BDNF mRNA is expressed in in HVC and another song nucleus, LMAN, but not in Area X or RA [78, 84]. Moreover, expression in $\mathrm{HVC}$ is both higher during breeding conditions compared to nonbreeding conditions in white-crowned sparrows [78] and is necessary [85] and sufficient [86] for increased addition of adult-born neurons in HVC in canaries. BDNF expression also positively correlates with increased singing behavior, both of which positively correlate with the number and survival of new neurons added in HVC [87]. Alternatively, deafening (i.e., loss of auditory neural activity) decreases neuronal addition to HVC in adult zebra finches [88]. These studies highlight the seemingly inextricable link between BDNF, singing behavior, and addition of adultborn neurons in HVC, and suggest a common factor, such as miR-132, may be coordinating the expression of breeding condition neurotrophin expression, cytoarchitecture, and behavior.

\section{The seasonal interaction network of miR-210 in Area $X$}

Of the significantly seasonally regulated miRs in Area $\mathrm{X}$ - another neurogenic and seasonally plastic song circuit nucleus - miR-210 stood out as a miR of interest. Given the role of miR-210 in promoting neural repair through angiogenesis [89-91], we investigated the miR-mRNA network of miR-210 more thoroughly. We first confirmed that the sequence of mature and seed regions of white-crowned sparrow miR-210 (i.e. zlg-mir-210) were $100 \%$ identical to hsa-mir-210 sequence (Additional file 1: Table S1 and Additional file 3: Figure S2). The full sequence of zlg-mir-210 was $67 \%$ identical to the full sequence of hsa-mir-210 (miRBase MI0000286), $67 \%$ to rno-mir-210 (miRBase MI0000950), and $82 \%$ to cli-mir210 (pigeon; NCBI RefSeq NW_004973526.1). A rooted phylogenetic tree placed the zlg-miR-210 sequence in the same clade as several other bird species including the collard-fly catcher (Ficedula albicollis) and the pigeon (Columbia livia; Additional file 3: Figure S2).

Using IPA's microRNA Target Prediction function we identified 1100 total targets of mir-210, 14 of which were differentially expressed (fold $>1.5, p<0.005$ ) as assessed by mRNA microarray analysis and inversely correlated in Area X. Two predicted target mRNAs were differentially expressed in Area X between SD and $\mathrm{LD}+\mathrm{T}$ at $21 \mathrm{D}$, while six were differentially expressed between SD and LDW (Fig. 5a). Examining the filtered targets across experimental groups for functional relatedness identified top significant canonical pathways related to dopamine signaling, phospholipase signaling, and calcium signaling (Table 3 ). Independent analyses of functional relatedness of miR-210 targets from LD + T 7D, 21D, and LDW identified top canonical pathways including serotonin, GABA, and dopamine receptor signaling, calcium transport, and lymphocyte signaling (Table 5 and Fig. 5b).

Although the mechanism through which $\mathrm{T}$ or its metabolites reduces miR-210 expression is unclear, our data suggests that miR-210 is indeed under sex steroid 
control. No previous reports find evidence of direct control of miR-210 expression by sex steroids. Alternatively, miR-210 regulation by $\mathrm{T}$ may be indirect: miR-210 expression is induced by HIF $\alpha$ [92], which is suppressed by estrogen [93], a metabolite of $T$. Thus, increased systemic $\mathrm{T}$, and its aromatization to estrogen, in Area $\mathrm{X}$ could prevent expression of HIF1 $\alpha$ thereby also preventing mir-210 expression.

Previous work found that miR-210 expression was significantly increased in glioma tissue and inhibition of miR-210 promoted glial cell proliferation and glioma cell apoptosis [94]. Alternatively, miR-210 has also been shown to reduce the inflammatory release of cytokines [95], to promote VEGF $[96,97]$ and Notch 1 [91] expression, and to increase endothelial cell and neural precursor cell proliferation [90]. These seemingly contrasting roles for miR-210 remain to be reconciled. Given these reports and that we find both proneurogenic and anti-apoptotic genes predicted miR-210 targets are up-regulated during LD + T, miR-210 expression in the brain may represent a fine-scaled dosedependent response to regulate levels of neural stem cell proliferation, neuronal versus glial fate specification, and cell survival.

\section{Conclusions}

We identified two seasonal miR-mRNA interaction networks that likely coordinate the various processes and factors related to the integration of new neurons in neural circuits and for the seasonal plasticity of the HVC to RA and HVC to Area X neural pathways. Highly differentially expressed miRs including, miR-132 and miR-210, likely target many gene products that are also seasonally regulated. Our data are not only consistent with previous reports of miR signaling networks and roles, but also suggest that sex steroids may regulate the processes of seasonal plasticity via alterations in miRmRNA expression networks. Herein, we provide opportunities to test novel genetic regulatory networks that control the diverse processes and mechanisms of functional incorporation of new neurons to the adult brain.

\section{Additional files}

Additional file 1: Table S1. Complete genomic sequences of miRs of interest from Gambel's white-crowned sparrow. (XLS $28 \mathrm{~kb}$ )

Additional file 2: Figure S1. Confirmation of miR-132 sequence. A) Rooted phylogenetic tree based on the genomic miR-132 sequences of other closely related and distantlyrelated vertebrates. B) The genomic miR-132 sequence of white-crowned sparrows aligned with other species in ClustalW. The white-crowned sparrow miR-132 sequence was most similar to zebra finch miR-132 and more distantly related to mammalian miR-132 sequences. Asterisks indicate conservation of the given nucleotide across species. The mature region of the zlg-miR-132 sequence (highlighted in blue) had $100 \%$ homology with the human sequence hsa-miR-132. (PDF $312 \mathrm{~kb}$ )
Additional file 3: Figure S2. Confirmation of miR-210 sequence. A) Rooted phylogenetic tree based on the genomic miR-210 sequence of other closely related and distantlyrelated vertebrates. B) The genomic miR-210 sequence of white-crowned sparrows aligned with other species in ClustalW. The white-crowned sparrow miR-210 sequence was most similar to the pigeon, fly catcher, and penguin miR-210. Asterisks indicate conservation of the given nucleotide across species. The mature region of the zlg-miR-210 sequence (highlighted in blue) had $100 \%$ homology with the human sequence hsa-miR-210. (PDF 325 kb)

Additional file 4: $\quad(X L S X 70 \mathrm{~kb})$

Additional file 5: Table S3. Significantly differentially expressed miRNAs $>2$ fold. (XLS $33 \mathrm{~kb}$ )

\section{Competing interests}

The authors declare no competing interests.

\section{Authors' contributions}

T.A.L., K.L.L., T.K.B, D.J.P., and E.A.B. designed research; T.A.L., K.L.L., W.E.W, M.L.C, N.M.T, A.B., D.J.P., and E.A.B performed research; T.A.L., T.K.B, and J.W.M. analyzed data; T.A.L. wrote manuscript; all authors edited manuscript. All authors read and approved the final manuscript.

\section{Acknowledgements}

Supported by NIH R01 MH53032 and R01 NS075331 to EAB; and National Research Service Award T32 GM007270 and T32 DC005361 to TAL. We also thank Agnes Bodor, Rachel Cohen, and Jesse Tsai for assistance with data collection and Dick Beyer, Fred Farin, and Ralf Luche for assistance with data interpretation.

\section{Author details}

'Department of Biology, University of Washington, Seattle, WA 98195, USA. ${ }^{2}$ Present Address: Basic Sciences Division, Fred Hutchinson Cancer Research Center, 1100 Fairview Ave N, Seattle, WA 98109, USA. ${ }^{3}$ Department of Psychology, University of Washington, Seattle, WA 98195, USA. ${ }^{4}$ Department of Environmental and Occupational Health Sciences, University of Washington, Seattle, WA 98195, USA. ${ }^{5}$ Department of Otolaryngology, University of Washington, Seattle, WA 98195, USA. ${ }^{6}$ Graduate Program in Neuroscience, University of Washington, Seattle, WA 98195, USA. ${ }^{7}$ Present address: Centre National de la Recherche Scientifique, Laboratoire de Neurophysique et Physiologie, UMR 8119, Université Paris Descartes, 45, rue des Saints Pères, 75006 Paris, France. ${ }^{8}$ Present address: Center for Neural Science, New York University, 4 Washington Place, New York, NY 10003, USA.

Received: 1 July 2015 Accepted: 31 October 2015

Published online: 06 November 2015

\section{References}

1. Alvarez-Buylla A, Theelen M, Nottebohm F. Proliferation "hot spots" in adult avian ventricular zone reveal radial cell division. Neuron. 1990;5(1):101-9

2. Reynolds BA, Weiss $S$. Generation of neurons and astrocytes from isolated cells of the adult mammalian central nervous system. Science. 1992;255(5052):1707-10.

3. Palmer TD, Takahashi J, Gage FH. The adult rat hippocampus contains primordial neural stem cells. Mol Cell Neurosci. 1997;8(6):389-404.

4. Vellema M, van der Linden A, Gahr M. Area-specific migration and recruitment of new neurons in the adult songbird brain. J Comp Neurol. 2010;518(9):1442-59.

5. Gage FH, Kempermann G, Song H. Adult neurogenesis, Cold spring harbor monograph series. Cold Spring Harbor: Cold Spring Harbor Laboratory Press; 2008. p. 673

6. Alvarez-Buylla A, Nottebohm F. Migration of young neurons in adult avian brain. Nature. 1988;335(6188):353-4

7. Burd GD, Nottebohm F. Ultrastructural characterization of synaptic terminals formed on newly generated neurons in a song control nucleus of the adult canary forebrain. J Comp Neurol. 1985;240(2):143-52.

8. Kirn JR, et al. Fate of new neurons in adult canary high vocal center during the first 30 days after their formation. J Comp Neurol. 1999;411(3):487-94. 
9. Scott $\mathrm{BB}$, et al. Wandering neuronal migration in the postnatal vertebrate forebrain. J Neurosci. 2012;32(4):1436-46.

10. Kirn JR, Alvarez-Buylla A, Nottebohm F. Production and survival of projection neurons in a forebrain vocal center of adult male canaries. J Neurosci. 1991;11(6):1756-62.

11. Nottebohm F, et al. The life span of new neurons in a song control nucleus of the adult canary brain depends on time of year when these cells are born. Proc Natl Acad Sci U S A. 1994;91(17):7849-53.

12. Walton $C$, Pariser $E$, Nottebohm F. The zebra finch paradox: song is little changed, but number of neurons doubles. J Neurosci. 2012;32(3):761-74

13. Brenowitz EA, Larson TA. Neurogenesis in the adult avian song-control system, Cold Spring Harb Perspect Biol. 2015. doi:10.1101/cshperspect.a019000.

14. Ambros $V$. The functions of animal microRNAs. Nature. 2004:431(7006):350-5.

15. Krichevsky AM, et al. A microRNA array reveals extensive regulation of microRNAs during brain development. RNA. 2003;9(10):1274-81.

16. Shinde S, Arora N, Bhadra U. A complex network of MicroRNAs expressed in brain and genes associated with amyotrophic lateral sclerosis. Int J Genomics. 2013;2013:383024.

17. Jin $P$, et al. Biochemical and genetic interaction between the fragile $X$ mental retardation protein and the microRNA pathway. Nat Neurosci. 2004;7(2):113-7.

18. Serafini $G$, et al. The role of microRNAs in synaptic plasticity, major affective disorders and suicidal behavior. Neurosci Res. 2012;73(3):179-90.

19. Beveridge NJ, et al. Dysregulation of miRNA $181 \mathrm{~b}$ in the temporal cortex in schizophrenia. Hum Mol Genet. 2008;17(8):1156-68.

20. Hebert SS, et al. MicroRNA regulation of Alzheimer's Amyloid precursor protein expression. Neurobiol Dis. 2009;33(3):422-8

21. Hsieh J, Gage FH. Epigenetic control of neural stem cell fate. Curr Opin Genet Dev. 2004;14(5):461-9.

22. Bicker $\mathrm{S}$, Schratt G. microRNAs: tiny regulators of synapse function in development and disease. J Cell Mol Med. 2008;12(5A):1466-76.

23. Magill ST, et al. microRNA-132 regulates dendritic growth and arborization of newborn neurons in the adult hippocampus. Proc Natl Acad Sci U S A. 2010;107(47):20382-7.

24. Luikart BW, et al. miR-132 mediates the integration of newborn neurons into the adult dentate gyrus. PLoS One. 2011;6(5):e19077.

25. Cimmino A, et al. miR-15 and miR-16 induce apoptosis by targeting BCL2. Proc Natl Acad Sci U S A. 2005;102(39):13944-9.

26. Scharff C, Nottebohm F. A comparative study of the behavioral deficits following lesions of various parts of the zebra finch song system: implications for vocal learning. J Neurosci. 1991;11(9):2896-913.

27. Thompson CK, Brenowitz EA. Seasonal change in neuron size and spacing but not neuronal recruitment in a basal ganglia nucleus in the avian song control system. J Comp Neurol. 2005;481(3):276-83.

28. Alvarez-Buylla A, Kirn JR, Nottebohm F. Birth of projection neurons in adult avian brain may be related to perceptual or motor learning. Science. 1990;249(4975):1444-6.

29. Scotto-Lomassese $\mathrm{S}$, et al. HVC interneurons are not renewed in adult male zebra finches. Eur J Neurosci. 2007;25(6):1663-8.

30. Alvarez-Buylla A, Theelen M, Nottebohm F. Birth of projection neurons in the higher vocal center of the canary forebrain before, during, and after song learning. Proc Natl Acad Sci U S A. 1988;85(22):8722-6.

31. Tramontin AD, Brenowitz EA. A field study of seasonal neuronal incorporation into the song control system of a songbird that lacks adult song learning. J Neurobiol. 1999;40(3):316-26.

32. Tramontin AD, Hartman VN, Brenowitz EA. Breeding conditions induce rapid and sequential growth in adult avian song control circuits: a model of seasonal plasticity in the brain. J Neurosci. 2000;20(2):854-61.

33. Thompson CK, Bentley GE, Brenowitz EA. Rapid seasonal-like regression of the adult avian song control system. Proc Natl Acad Sci U S A. 2007;104(39):15520-5.

34. Thompson CK, Brenowitz EA. Caspase inhibitor infusion protects an avian song control circuit from seasonal-like neurodegeneration. J Neurosci. 2008;28(28):7130-6.

35. Larson TA, et al. Reactive neurogenesis in response to naturally occurring apoptosis in an adult brain. J Neurosci. 2014:34(39):13066-76.

36. Alvarez-Borda B, Nottebohm F. Gonads and singing play separate, additive roles in new neuron recruitment in adult canary brain. J Neurosci. 2002;22(19):8684-90.
37. Meitzen J, et al. Time course of changes in Gambel's white-crowned sparrow song behavior following transitions in breeding condition. Horm Behav. 2009;55(1):217-27.

38. Meitzen J, Perkel DJ, Brenowitz EA. Seasonal changes in intrinsic electrophysiological activity of song control neurons in wild song sparrows. J Comp Physiol A Neuroethol Sens Neural Behav Physiol. 2007;193(6):677-83.

39. Meitzen J, et al. Plastic and stable electrophysiological properties of adult avian forebrain song-control neurons across changing breeding conditions. J Neurosci. 2009;29(20):6558-67.

40. Thompson CK, et al. Seasonal changes in patterns of gene expression in avian song control brain regions. PLoS ONE. 2012;7(4), e35119.

41. Brenowitz EA, Lent K, Rubel EW. Auditory feedback and song production do not regulate seasonal growth of song control circuits in adult white-crowned sparrows. J Neurosci. 2007;27(25):6810-4

42. Meitzen J, et al. Steroid hormones act transsynaptically within the forebrain to regulate neuronal phenotype and song stereotypy. J Neurosci. 2007;27(44):12045-57.

43. Warren WC, et al. The genome of a songbird. Nature. 2010;464(7289):757-62.

44. Whitney $\mathrm{O}$, et al. Core and region-enriched networks of behaviorally regulated genes and the singing genome. Science. 2014;346(6215):1256780.

45. Huber W, et al. Variance stabilization applied to microarray data calibration and to the quantification of differential expression. Bioinformatics. 2002;18 Suppl 1:S96-S104

46. Irizarry RA, Gautier L, Cope L. An R package for analyses of affymetrix oligonucleotide arrays. In: Parmigiani G et al., editors. The analysis of gene expression data. London: Springer; 2003. p. 102-19.

47. Gentleman RC, et al. Bioconductor: open software development for computational biology and bioinformatics. Genome Biol. 2004;5(10):R80.

48. Smyth GK. Linear models and empirical bayes methods for assessing differential expression in microarray experiments. Stat Appl Genet Mol Biol. 2004;3:Article3

49. Ritchie ME, et al. Empirical array quality weights in the analysis of microarray data. BMC Bioinformatics. 2006;7:261.

50. Replogle K, et al. The Songbird Neurogenomics (SoNG) Initiative: community-based tools and strategies for study of brain gene function and evolution. BMC Genomics. 2008:9:131.

51. Hilliard AT, et al. Molecular microcircuitry underlies functional specification in a basal ganglia circuit dedicated to vocal learning. Neuron. 2012;73(3):537-52.

52. Gunaratne $\mathrm{PH}$, et al. Song exposure regulates known and novel microRNAs in the zebra finch auditory forebrain. BMC Genomics. 2011;12(1):277.

53. Issler $\mathrm{O}$, et al. MicroRNA 135 is essential for chronic stress resiliency, antidepressant efficacy, and intact serotonergic activity. Neuron. 2014;83(2):344-60

54. Wood WE, et al. Serotonin, via HTR2 receptors, excites neurons in a corticallike premotor nucleus necessary for song learning and production. $J$ Neurosci. 2011;31(39):13808-15

55. Wood WE, Roseberry TK, Perkel DJ. HTR2 receptors in a songbird premotor cortical-like area modulate spectral characteristics of zebra finch song. J Neurosci. 2013;33(7):2908-15.

56. Liu C, et al. Epigenetic regulation of miR-184 by MBD1 governs neural stem cell proliferation and differentiation. Cell Stem Cell. 2010;6(5):433-44.

57. Petersen $\mathrm{PH}$, et al. Progenitor cell maintenance requires numb and numblike during mouse neurogenesis. Nature. 2002;419(6910):929-34.

58. Zhong W, et al. Differential expression of mammalian Numb, Numblike and Notch1 suggests distinct roles during mouse cortical neurogenesis. Development. 1997;124(10):1887-97.

59. Fu L, et al. Multiple microRNAs regulate human FOXP2 gene expression by targeting sequences in its $3^{\prime}$ untranslated region. Mol Brain. 2014;7:71.

60. Vernes SC, et al. High-throughput analysis of promoter occupancy reveals direct neural targets of FOXP2, a gene mutated in speech and language disorders. Am J Hum Genet. 2007:81(6):1232-50.

61. Haesler S, et al. FoxP2 expression in avian vocal learners and non-learners. $J$ Neurosci. 2004:24(13):3164-75.

62. Vernes SC, et al. Foxp2 regulates gene networks implicated in neurite outgrowth in the developing brain. PLoS Genet. 2011;7(7), e1002145.

63. Shi Z, et al. miR-9 and miR-140-5p target FoxP2 and are regulated as a function of the social context of singing behavior in zebra finches. J Neurosci. 2013;33(42):16510-21. 
64. Remenyi J, et al. Regulation of the miR-212/132 locus by MSK1 and CREB in response to neurotrophins. Biochem J. 2010;428(2):281-91.

65. Liu H, et al. MiR-212-3p inhibits glioblastoma cell proliferation by targeting SGK3. J Neurooncol. 2015;122(3):431-9. doi:10.1007/s11060-015-1736-y.

66. Ryan KM, O'Donovan SM, McLoughlin DM. Electroconvulsive stimulation alters levels of BDNF-associated microRNAs. Neurosci Lett. 2013;549:125-9.

67. Nakamura K, et al. Effects of single and repeated electroconvulsive stimulation on hippocampal cell proliferation and spontaneous behaviors in the rat. Brain Res. 2013;1491:88-97.

68. Weber T, et al. Genetic fate mapping of type-1 stem cell-dependent increase in newborn hippocampal neurons after electroconvulsive seizures. Hippocampus. 2013;23(12):1321-30.

69. Chen Y, Liersch R, Detmar M. The miR-290-295 cluster suppresses autophagic cell death of melanoma cells. Sci Rep. 2012;2:808.

70. Gao J, et al. A novel pathway regulates memory and plasticity via SIRT1 and miR-134. Nature. 2010;466(7310):1105-9.

71. Jimenez-Mateos EM, et al. Silencing microRNA-134 produces neuroprotective and prolonged seizure-suppressive effects. Nat Med. 2012:18(7):1087.

72. Clovis YM, et al. Convergent repression of Foxp2 3'UTR by miR-9 and miR132 in embryonic mouse neocortex: implications for radial migration of neurons. Development. 2012;139(18):3332-42.

73. Luo GZ, et al. Genome-wide annotation and analysis of zebra finch microRNA repertoire reveal sex-biased expression. BMC Genomics. 2012;13(1):727

74. Pizzorusso T, et al. Brain-derived neurotrophic factor causes CAMP response element-binding protein phosphorylation in absence of calcium increases in slices and cultured neurons from rat visual cortex. J Neurosci. 2000;20(8):2809-16.

75. Obrietan K, et al. Circadian regulation of CAMP response element-mediated gene expression in the suprachiasmatic nuclei. J Biol Chem. 1999:274(25):17748-56.

76. Hardingham GE, Arnold FJ, Bading H. Nuclear calcium signaling controls CREB-mediated gene expression triggered by synaptic activity. Nat Neurosci. 2001;4(3):261-7.

77. Yi LT, et al. BDNF-ERK-CREB signalling mediates the role of miR-132 in the regulation of the effects of oleanolic acid in male mice. J Psychiatry Neurosci. 2014;39(5):348-59.

78. Wissman AM, Brenowitz EA. The role of neurotrophins in the seasonal-like growth of the avian song control system. J Neurosci. 2009;29(20):6461-71.

79. Louissaint Jr A, et al. Coordinated interaction of neurogenesis and angiogenesis in the adult songbird brain. Neuron. 2002:34(6):945-60

80. Auger CJ, et al. Expression of CAMP response element binding proteinbinding protein in the song control system and hypothalamus of adult European starlings (Sturnus vulgaris). J Neuroendocrinol. 2002;14(10):805-13.

81. Aarnisalo P, Palvimo JJ, Janne OA. CREB-binding protein in androgen receptor-mediated signaling. Proc Natl Acad Sci U S A. 1998;95(5):2122-7.

82. Wang J, et al. miR-132 targeting cyclin E1 suppresses cell proliferation in osteosarcoma cells. Tumour Biol. 2014;35(5):4859-65.

83. Anand $\mathrm{S}$, et al. MicroRNA-132-mediated loss of p120RasGAP activates the endothelium to facilitate pathological angiogenesis. Nat Med. 2010;16(8):909-14

84. Dittrich F, et al. Estrogen-inducible, sex-specific expression of brain-derived neurotrophic factor mRNA in a forebrain song control nucleus of the juvenile zebra finch. Proc Natl Acad Sci U S A. 1999:96(14):8241-6.

85. Alvarez-Borda B, Haripal B, Nottebohm F. Timing of brain-derived neurotrophic factor exposure affects life expectancy of new neurons. Proc Natl Acad Sci U S A. 2004;101(11):3957-61.

86. Rasika S, Alvarez-Buylla A, Nottebohm F. BDNF mediates the effects of testosterone on the survival of new neurons in an adult brain. Neuron 1999;22(1):53-62.

87. Li XC, et al. A relationship between behavior, neurotrophin expression, and new neuron survival. Proc Natl Acad Sci U S A. 2000;97(15):8584-9.

88. Wang N, Aviram R, Kirn JR. Deafening alters neuron turnover within the telencephalic motor pathway for song control in adult zebra finches. Neurosci. 1999;19(23):10554-61.

89. Zaccagnini $\mathrm{G}$, et al. Hypoxia-induced miR-210 modulates tissue response to acute peripheral ischemia. Antioxid Redox Signal. 2014;21(8):1177-88.

90. Zeng $L$, et al. MicroRNA-210 overexpression induces angiogenesis and neurogenesis in the normal adult mouse brain. Gene Ther. 2014;21(1):37-43.
91. Lou $Y L$, et al. miR-210 activates notch signaling pathway in angiogenesis induced by cerebral ischemia. Mol Cell Biochem. 2012;370(1-2):45-51.

92. Camps $C$, et al. hsa-miR-210 Is induced by hypoxia and is an independent prognostic factor in breast cancer. Clin Cancer Res. 2008;14(5):1340-8.

93. Nickel EA, et al. Estrogen suppresses cardiac IL-6 after trauma-hemorrhage via a hypoxia-inducible factor 1 alpha-mediated pathway. Shock. 2009;31(4):354-8.

94. Shang C, et al. MiR-210 up-regulation inhibits proliferation and induces apoptosis in glioma cells by targeting SIN3A. Med Sci Monit. 2014;20:2571-7.

95. Qi J, et al. microRNA-210 negatively regulates LPS-induced production of proinflammatory cytokines by targeting NF-kappaB1 in murine macrophages. FEBS Lett. 2012;586(8):1201-7.

96. Liu SC, et al. CTGF increases vascular endothelial growth factor-dependent angiogenesis in human synovial fibroblasts by increasing miR-210 expression. Cell Death Dis. 2014;5, e1485.

97. Liu XD, et al. microRNA-210 is involved in the regulation of postmenopausal osteoporosis through promotion of VEGF expression and osteoblast differentiation. Biol Chem. 2015;396(4):339-47. doi:10.1515/hsz-2014-0268.

\section{Submit your next manuscript to BioMed Central and take full advantage of:}

- Convenient online submission

- Thorough peer review

- No space constraints or color figure charges

- Immediate publication on acceptance

- Inclusion in PubMed, CAS, Scopus and Google Scholar

- Research which is freely available for redistribution

Submit your manuscript at www.biomedcentral.com/submit 